\title{
Duration of treatment for osteoporosis
}

\author{
L. Idolazzi, A. Fassio, D. Gatti, S. Tamanini, O. Viapiana, \\ M. Rossini, S. Adami \\ Rheumatology Unit, University of Verona, Italy
}

\section{SUMMARY}

Many treatments for postmenopausal osteoporosis with proven efficacy in lowering fracture risk had become available since many years now. In the last few years the issue about treatment duration has become a matter of importance. In this paper the pivotal trials for alendronate, risedronate, zoledronate and other anti reabsorptive drugs such as denosumab are revised with particular attention to the extension studies aimed to verify the effect of drug discontinuation. The results of the review highlight differences among the available drugs and the practical clinical consequences also in terms of cost-effectiveness.

Key words: Osteoporosis, duration, treatment, alendronate, denosumab.

Reumatismo, 2013; 65 (1): 22-35

\section{INTRODUCTION}

Cince several years many treatments $\checkmark$ ince several years many treatments for postmenopausal osteoporosis with proven efficacy in lowering fracture risk have been available. Pharmacological treatment for osteoporosis is only indicated when fracture risk is considered unacceptably high (1) and it should be continued until the fracture risk remains high as just already recommended for the management of diabetes or blood hypertension. However, for osteoporosis the issue appears to be much more complicated for a number of reasons. Differently from diabetes and hypertension, drugs for osteoporosis can bring persistent structural benefits. For some of these drugs, i.e. teriparatide (a drug with anabolic properties on bone) the length of the treatment was set to 24 months. The original rationale of this limited duration was linked to concerns on the potential teratogenicity of the drug, but it is also justified by the risk of favouring bone growth in sites where it is not desirable (osteophytes), a concern shared also by every anabolic drug, included those in development such as anti-sclerostin antibodies.

Anti-absorptive drugs (bisphosphonates, oestrogens, SERMS and denosumab) registered for the treatment of postmenopausal osteoporosis decrease bone turnover. This suppression is associated with increased skeletal mineralization and prevention of bone loss. The anti-fracture effect is also based upon the suppression of turnover "per se" (2) which is reverted after treatment discontinuation; from this point of view, this would suggest that treatment with these drugs should never go beyond the effect on bone turnover.

The issue of the treatment duration for anti-reabsorptive drugs arise from the potential risk related with long-term treatment. Thus, the duration of hormone replacement therapy is limited by the risk of breast cancer and bisphosphonates and denosumab for the associated risk of jaw osteomyelitis, called also osteonecrosis of the jaw (ONJ) and of atypical sub-trochanteric fractures. These are extremely rare adverse events which do not hamper the positive benefit/ drawback ratio. Treatment discontinuation may obviously lead to increased risk of fracture within a time-frame which might be considerably different among available therapies.

In this article we will summarize the available data concerning the consequences of anti-reabsorptive treatment discontinuation and then discuss the guidelines to follow, referring to the views recently raised by NIH in the USA (3). 


\section{ALENDRONATE:} PHASE 3 STUDY

The first phase 3 study with Alendronate (ALN) (4) for the treatment of post-menopausal osteoporosis (PMO) included 3 arms: placebo, ALN $5 \mathrm{mg} / \mathrm{day}$ and $10 \mathrm{mg} /$ die. The placebo arm was abandoned after 3 years, while patients on ALN continued treatment for 2 more years. At the end of the fifth year patients on $10 \mathrm{mg} /$ day were randomized to continue the treatment or to stop it with a 5 additional years of followup (5). BMD increase clearly dissociated between the two ALN dosages after the first year and for this reason all patients on ALN were put on $10 \mathrm{mg}$ /day (6).

In the patients who took ALN $10 \mathrm{mg} / \mathrm{die}$ for 10 years, lumbar spine BMD rapidly increased after the first year $(+5,5 \%)$ and this was followed by a progressive increase of $1.5 \%$ per year still well visible at the $10^{\text {th }}$ year of observation. Femoral BMD increased rapidly during the first 2 years (about $+5 \%$ ) and this was followed by slight increase (about $0.1 \%$ per year). In patients who discontinued treatment with ALN, lumbar spine BMD remained unchanged over the 5 years follow-up, but femoral BMD decreased within one year since treatment cessation. After 5 years of follow-up the mean difference versus baseline in lumbar and femoral BMD in the two groups was $4.8 \%$ and $1.8 \%$, respectively (Fig. 1).

For a subset of patients the measurement of bone resorption marker (urine NTX) and bone formation markers (bone alkaline phosphatases or BALP) was available. At variance with $\mathrm{BMD}$, bone turnover markers quickly increased within the first year since treatment discontinuation. It is still difficult to understand whether bone turnover markers returned fully back to basal levels considering the effect of supplementation with calcium and vitamin D which were continued in all patients. From the data of the placebo group during the first 3 years while on treatment only with calcium and vitamin D it seems that all bone turnover markers remain somewhat suppressed by $10-20 \% 5$ years after treatment discontinuation. Patients included in the extension of the study were absolutely insufficient for any analysis on the consequences of treatment cessation on the incidence of osteoporotic fractures (Fig. 1).

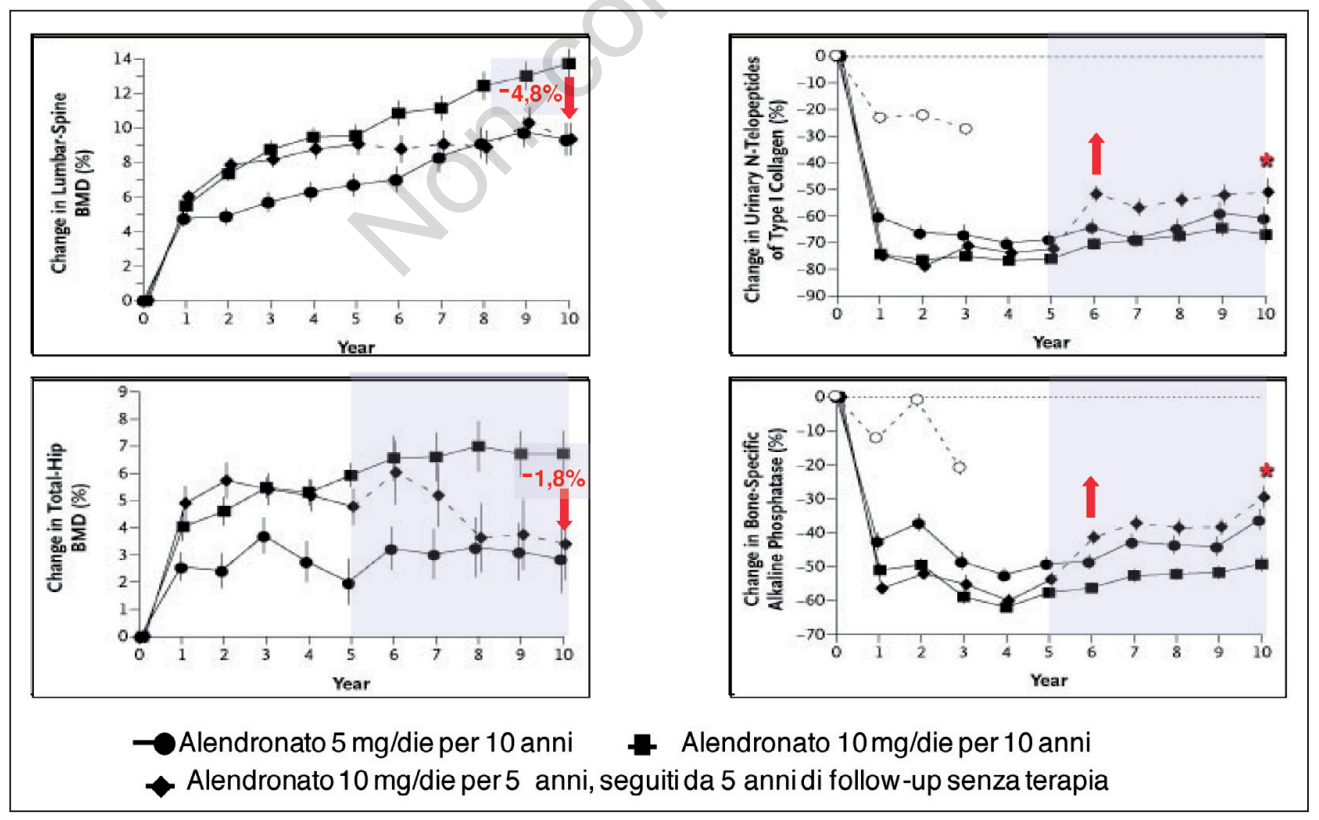

Figure 1 - Variations of femoral or lumbar spine BMD and of two bone turnover markers (urine NTX or bone alkaline phosphatases) in the extension of phase 3 study with Alendronate in post-menopausal osteoporosis (5). 


\section{Conclusions}

the extent of the phase 3 study with ALN shows that the cessation of ALN treatment is associated with a long-term persistence of the positive BMD effects particularly at the lumbar spine BMD even if lower than those observed in patients who continued treatment for 10 years. Bone turnover went back to nearly basal levels in 12 months.

\section{ALENDRONATE: FLEX STUDY}

The FIT pivotal trial of ALN for PMO (FIT study) (6), included globally 6459 patients with only moderate osteoporosis (6-8). For the first time an anti-fracture efficacy was demonstrated for a treatment based on an anti-reabsorptive drug in patients with postmenopausal osteoporosis (7). Even though ALN has been the first drug included in the Italian regulation for refound (Nota 79) the drugs till offers the best data of effectiveness on fracture risk (Tab. I).

The FIT study with the inclusion of a placebo group was extended for 4 years. Four months after the end of the controlled trial,approximately one thousand patients were randomized to continue treatment with 5 or $10 \mathrm{mg} / \mathrm{die}$ ALN or placebo in the FLEX study (9) with 5 years of additional follow up. No relevant differences were noted between patients on treatment with 5 or $10 \mathrm{mg}$, so the two groups were analysed together versus placebo.

In treated patients lumbar spine BMD increased continuously by about $1 \%$ per year while femoral BMD remained stable or it slightly decreased. In the placebo patients lumbar spine BMD remained substantially stable, while hip BMD decreased to pretreatment levels, even though about 10 years later and when patients were 10 year older. At the end of the follow-up for the FLEX study the difference between treated and non-treated patients was 3.8\% and $2.4 \%$ for lumbar spine BMD and hip BMD, respectively (Fig. 2).

Bone turnover markers remained suppressed in patients who continued treatment while they gradually went back to basal levels (pre-FIT) in placebo patients (Fig. 2).

\section{Conclusions}

The results of the FLEX study related to BMD and bone turnover markers are comparable with those observed in the phase 3 study with ALN. After treatment discontinuation bone turnover increased quickly within the first 6 months and then more slowly with the restoration of the original pre-treatment values within 5 years. This observation might be of help for identifying, for example, the lag time between treatment discontinuation and dental intervention in order to minimize the risk of ONJ.

The FLEX study included 662 patients treated with ALN and 437 kept on placebo. Assuming a fracture incidence of $20 \%$ in the placebo group, the study had an $80 \%$ "statistic power" for detecting a difference in the fracture risk of $13-33 \%$.

The final results did not show differences between the two groups concerning every

Table I - Relative risk reduction (RRR \%) for vertebral, non-vertebral and femoral fractures from Cochrane meta-analysis (alendronate, risedronate and strontium ranelate) or from single pivotal trials (raloxifene, basedoxifene) for drugs included in the Nota 79. Ibandronate has been commercialized at a dose almost double than that used in the registrative trials.

\begin{tabular}{|l|l|l|l|}
\hline Medication & RRR vertebral fractures & RRR non-vertebral fractures & RRR femoral fractures \\
\hline Alendronate & $45 \%$ & $23 \%$ & $40 \%$ \\
\hline Risedronate & $39 \%$ & $20 \%$ & $26 \%$ \\
\hline Ibandronate & $56 \%$ & $0 \%$ & $0 \%$ \\
\hline Strontium ranelate & $37 \%$ & $14 \%$ & $15 \%$ \\
\hline Raloxifene & $35 \%$ & $8 \%(\mathrm{NS})$ & 0 \\
\hline Basedoxifene & $42 \%$ & $9 \%$ & 0 \\
\hline
\end{tabular}




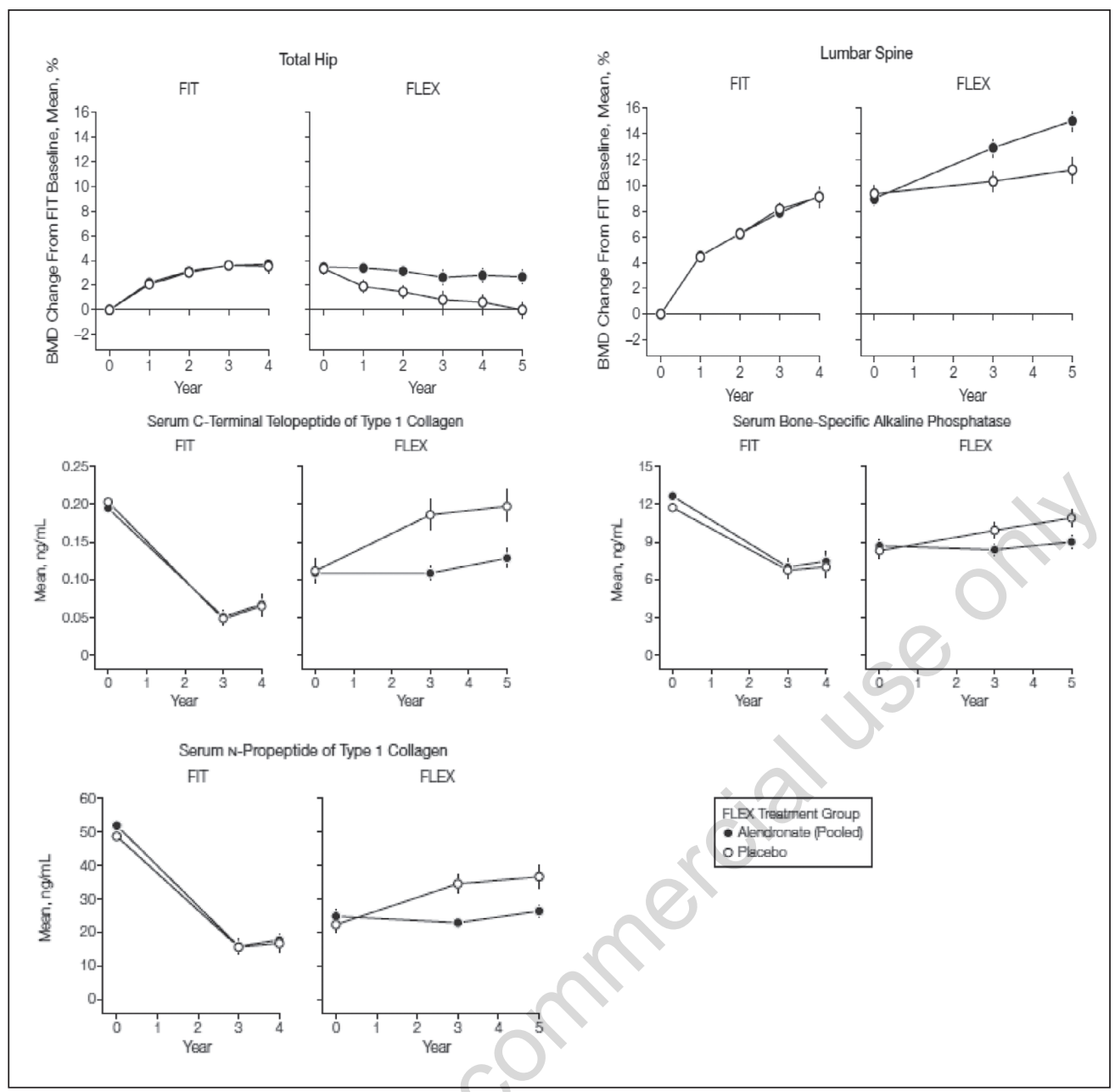

Figure 2 - Densitometric and bone turnover marker variations during the FIT study (Alendronate in postmenopausal osteoporosis) and its extension in the FLEX study. In the FLEX study patients previously treated with Alendronate were randomized to continue Alendronate or to placebo (9).

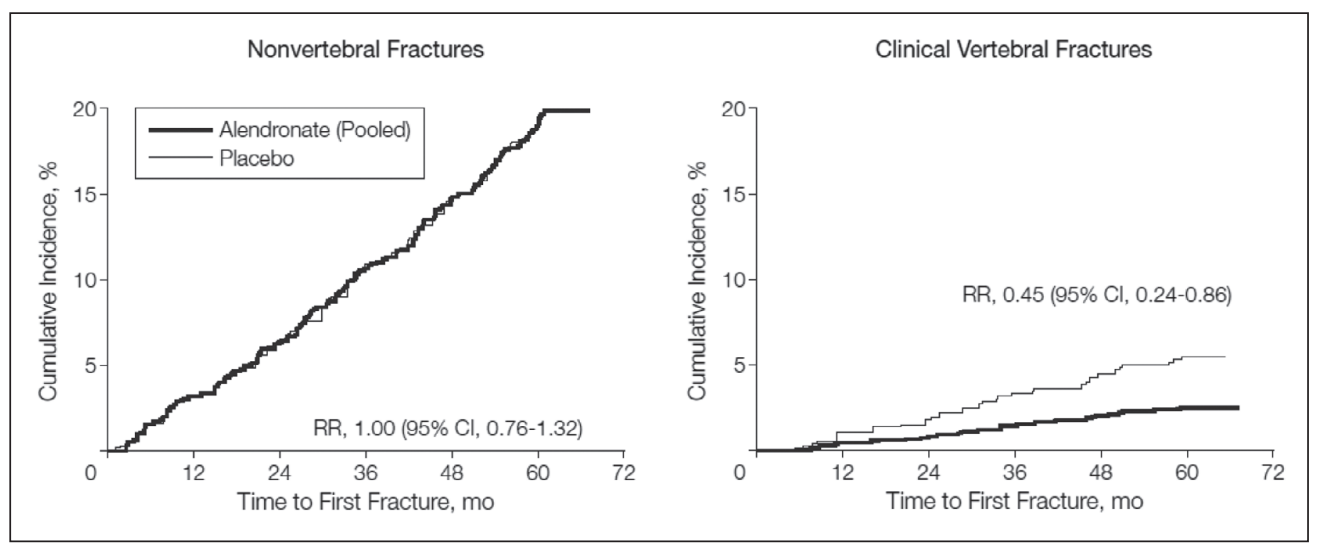

Figure 3 - Fracture incidence in the FLEX study, the extension of the FIT study only for previously treated patients with Alendronate (9). 


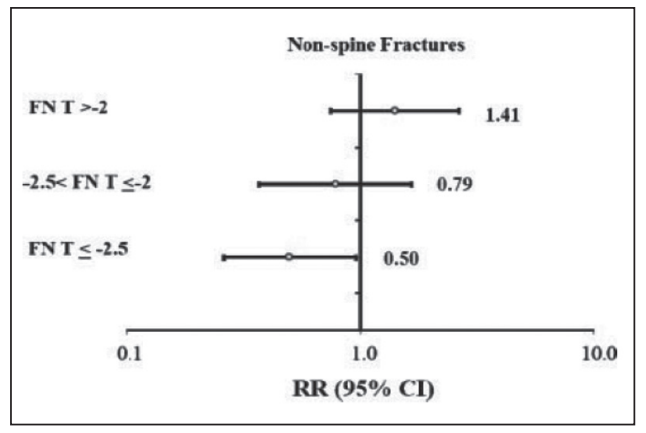

Figure 4 - Relative risk (RR) of non-vertebral fractures during FLEX study (Alendronate versus placebo) in patients ranked according with femoral neck BMD (T-score) values. In patient with persistent osteoporosis (T-score $<-2.5)$ prosecution of treatment leads to an additional advantage also for non-vertebral fractures (10).

type of fracture. However a statistically $55 \%$ significant difference was observed for clinical vertebral fracture risk, i.e.: the fractures diagnosed for the appearance of obvious symptoms. The risk of morphometric vertebral fractures was reduced by 14\% (Fig. 3).

Results relative to incidence of non-vertebral fractures were re-analysed afterwards, dividing patients according to the severity of osteoporosis at the moment of inclusion in the FLEX study (10). Among patients with diagnosis of osteoporosis according to the WHO (T score <-2.5), treatment with ALN was also associated with a significant $50 \%$ risk reduction of non-vertebral fractures (Fig. 4).

\section{RISEDRONATE: EXTENSION OF THE PIVOTAL TRIALS}

The clinical development of Risedronate (RIS) included 3 studies. One study was designed to verify the effectiveness on femoral fracture risk (HIP study) (11). The two studies with the goal of evaluating vertebral fracture risk reduction (VERT studies) were conducted one in North America (VERTNA) (12) and one in other countries (VERTMN) (13). The VERT-NA study included a follow-up of one year after 3 years "in blind" for RIS $5 \mathrm{mg}$ /die or placebo (14). In the active group the cessation of treatment was associated with a significant decrease within a year of the densitometric values to almost pre-treatment values for femoral BMD while urine NTX (bone reabsorption marker) quickly returned to the values of the patients on treatment only with supplements of calcium and vitamin D.

Even if the duration of ALN treatment was slightly longer, the difference between the two bisphosphonates appears to be quite evident. The tail-effect of ALN is about 5

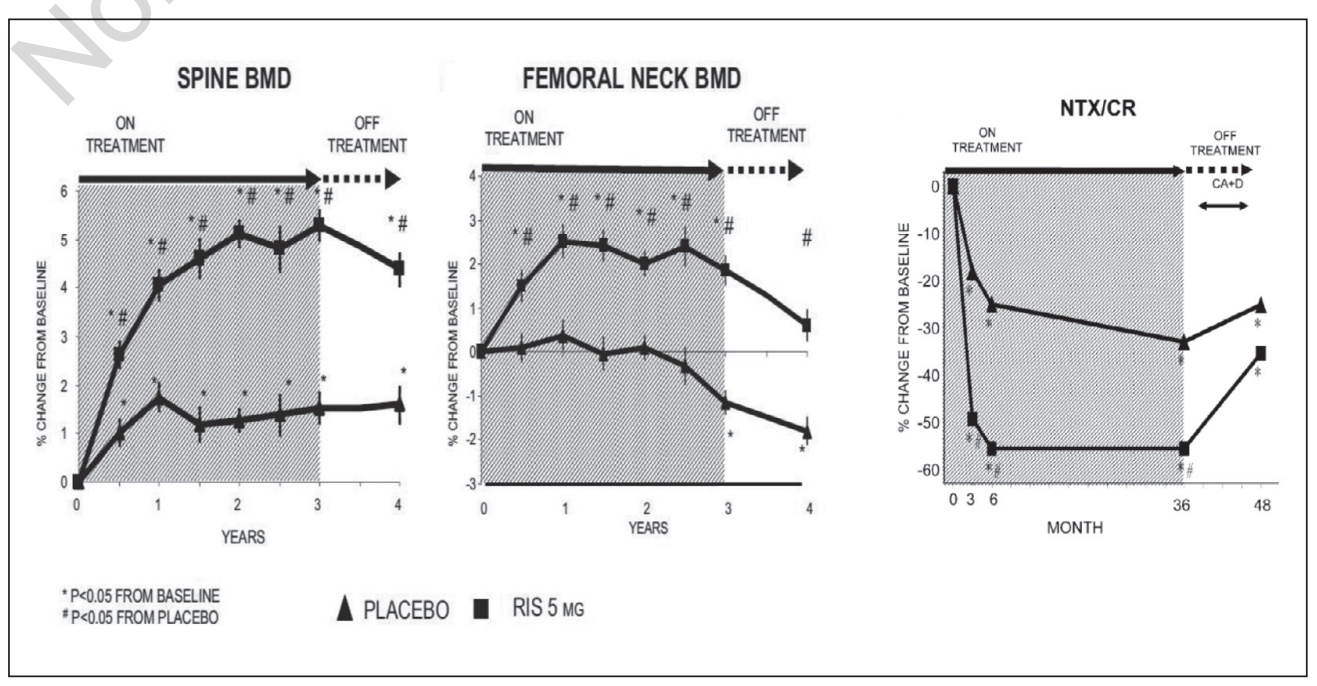

Figure 5 - Variation of BMD and urine NTX values during VERN NA study and its extension $(12,14)$. 
times longer: the return to pre-treatment levels of bone turnover and BMD occurs after about one year in patients treated with RIS and after about 5 years in those treated with ALN for 4 years (Fig. 5).

The extension of VERT-MN study was significantly more complex (15). The effect of treatment discontinuation was studied in patients previously treated for 7 and for 2 years with RIS. The duration of previous treatment was not associated with appreciable differences in term of resolution of the effect. The return to pre-treatment values of femoral neck BMD occurred within 2 years, while urine NTX levels returned to basal levels within 6 months, as for the VERT-NA study (Fig. 6).

\section{Conclusions}

ALN and RIS clearly differ regarding the tail effect in the clinical setting of trials differing marginally each-other. It is about 5 times longer for ALN: the return to pretreatment levels of bone turnover and BMD occurs after about 1 year in patients treated with RIS and 5 years in those treated for 4 years with ALN. The duration of the treatment with RIS does not affect the duration of the tail effect.

\section{ZOLEDRONATE: EXTENSION STUDIES}

The original pivotal trial HORIZON with Zoledronic Acid (ZOL) versus placebo was extended for 3 years (16). The patients in the active group received 3 infusions of ZOL $4 \mathrm{mg}$. At the end of this period the patients of the active group were randomized to continue or not the treatment with a 3 years follow-up. Densitometric difference between the two groups after the 3 years of follow-up was ca. 1-2\% due to marginal decrease in femoral neck BMD in untreated patients and to constant increases of lumbar spine BMD in patients who received two additional ZOL infusions (Fig. 7) (17). During the 3 years of follow-up, the two groups were undistinguishable in terms of new non-vertebral fractures incidence, while the incidence of vertebral fracture was significantly reduced by treatment continuation (Fig. 8) (17). From a recent sub-analysis (18) emerged that in the patients who received only one infusion of the drug, the reduction of clinical fracture risk (of any kind) was equal $(-32 \%)$ to that observed in the patients who received three infusions.

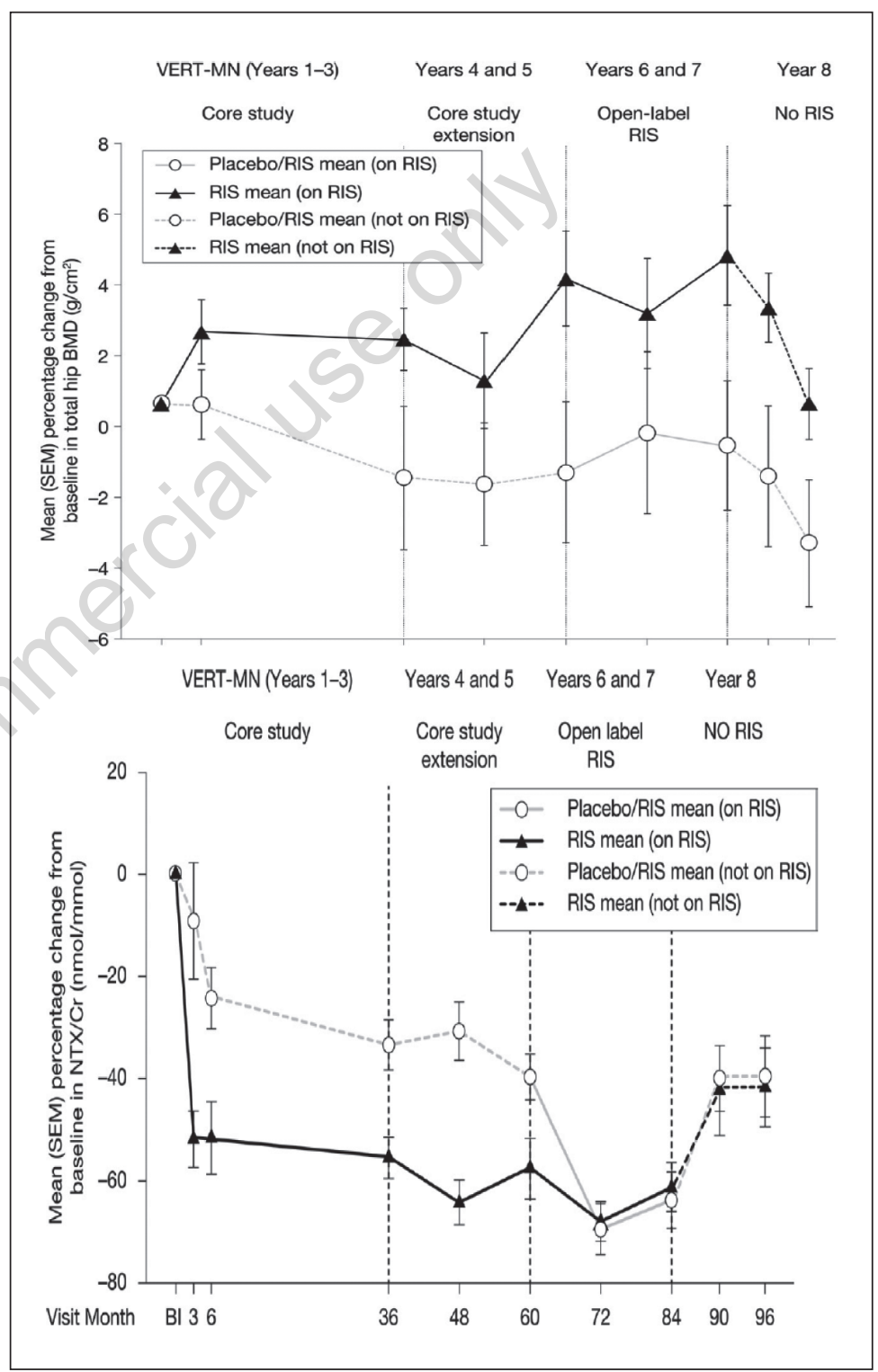

Figure 6 - Changes in femoral neck BMD and urine NTX in patients of VERT-MN study participating in the extension study. The open circle and the black triangle indicate the patients randomized to placebo and Risedronate respectively, in the first three years of the trial. The dashed line indicates the period in which the patients were on placebo and the continuous line patients when assuming RIS (15). 


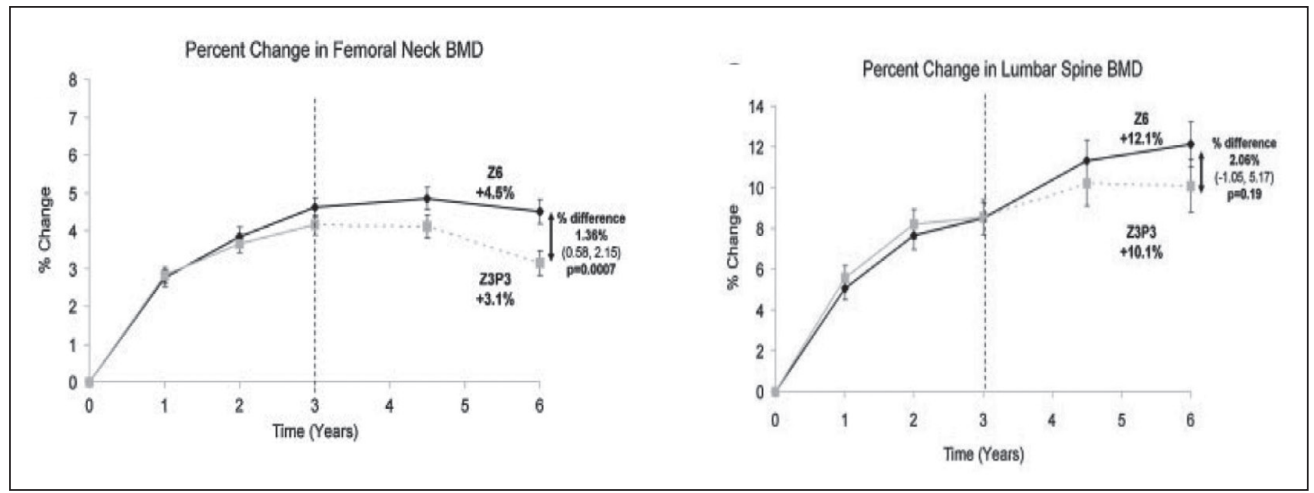

Figure 7 - Densitometric variations in the extension study with ZOL. The patients treated during the first three years with ZOL were randomized to continue or not treatment (17).
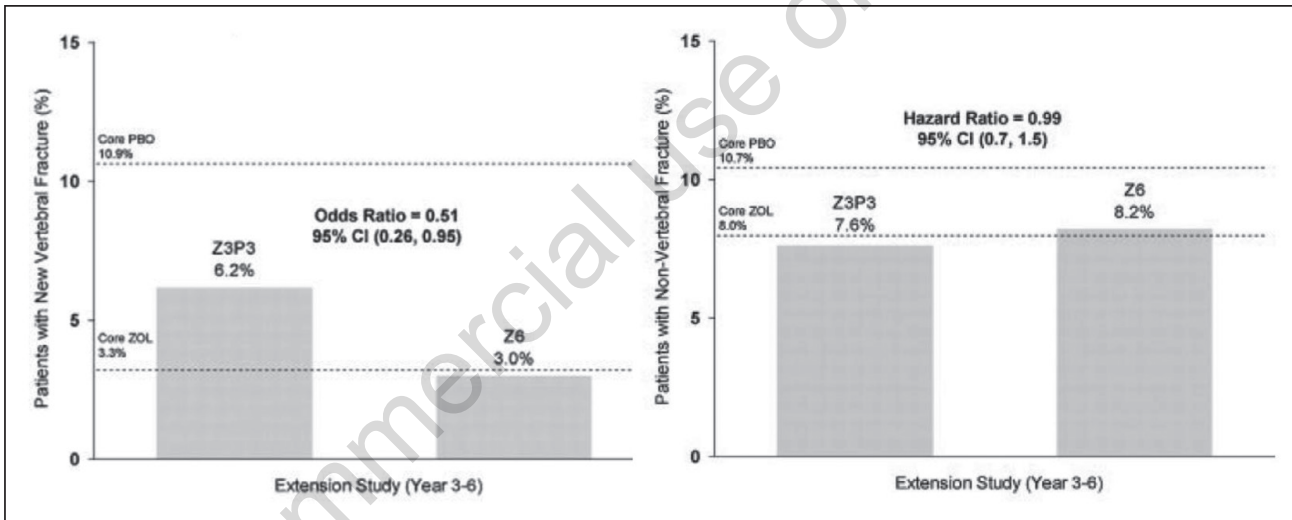

Figure 8 - Vertebral and non-vertebral fracture incidence in patients in the extension trial with ZOL. The patients treated in the first three years with ZOL were randomized to continue (Z6) or not (Z3P3) treatment (17).

\section{Conclusions}

The tail effect of ZOL appears to be quite important and apparently superior to that observed with ALN. Also with ZOL treatment discontinuation is associated with a partial loss of efficacy on vertebral fracture risk but not for non-vertebral fractures.

\section{EXTENSION OF REGISTRATIVE TRIALS WITH OTHER ANTI-RESORPTIVES}

Available data on the tail effect of Ibandronate are very few and limited do phase 2 studies (19). The emerging pattern is a clear resemblance with RIS, with the restoration of bone turnover within 6-12 months from treatment cessation (Fig. 9). There is no tail effect for treatment with estrogens and SERMS (Raloxifene and Basedoxifene) since with their discontinuation bone turnover returns to basal levels within a few weeks and all densitometric increases observed during treatment are lost within one year (20). The effect of anti-RANKL treatment with Denosumab is lost in a few weeks both for bone turnover markers and for densitometric increase (Fig. 10) (21). Data regarding the consequences of discontinuation of the treatment with Strontium Ranelate are limited and inconclusive due to the tiny variations of bone turnover markers observed during treatment. The densitometric increases observed during treatment are related to an undefined effect 


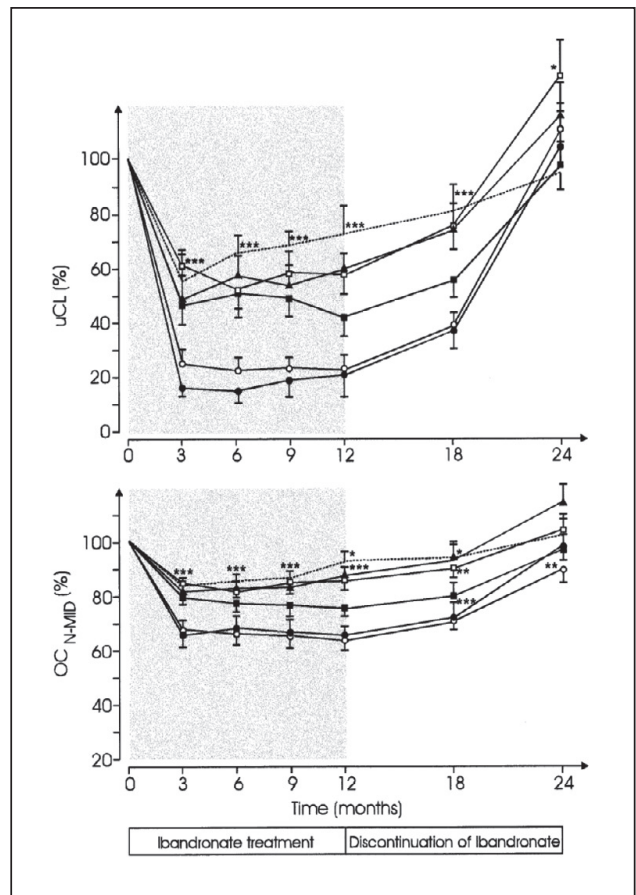

Figure 9 - Bone turnover markers variation after ceasing of the treatment with Ibandronate (19).

of the atomic weight of Strontium (much higher than that of calcium) absorbed in the bone tissue. This uncertainty is inevitably conveyed also to the interpretation of the changes in BMD after treatment discontinuation.

\section{DISCUSSION}

The impact of treatment discontinuation in postmenopausal osteoporosis varies considerably in relation with the adopted treatment. Four distinct scenarios should be considered:

\section{Teriparatide discontinuation}

There's now a very large agreement about the need for starting treatment with antireabsorptive drugs soon after the treatment course with Teriparatide to save and empower the acquired benefits $(22,23)$.

\section{Denosumab discontinuation}

In patients treated with Denosumab, treatment discontinuation is followed by s a rebound of bone turnover with an impact on fracture risk poorly understood (24). In patients at very high risk (as those identified by the Italian "Nota 79") (25) it is probably appropriate to recommend a therapeutic cycle with bisphosphonates immediately after Denosumab discontinuation, if a rebound in fracture rate is feared.

\section{Estrogens or SERMS discontinuation}

After discontinuation of hormones bone turnover and BMD return within a few weeks to pre-treatment levels. Therefore a re-assessment about the opportunity of resuming a treatment is warranted.

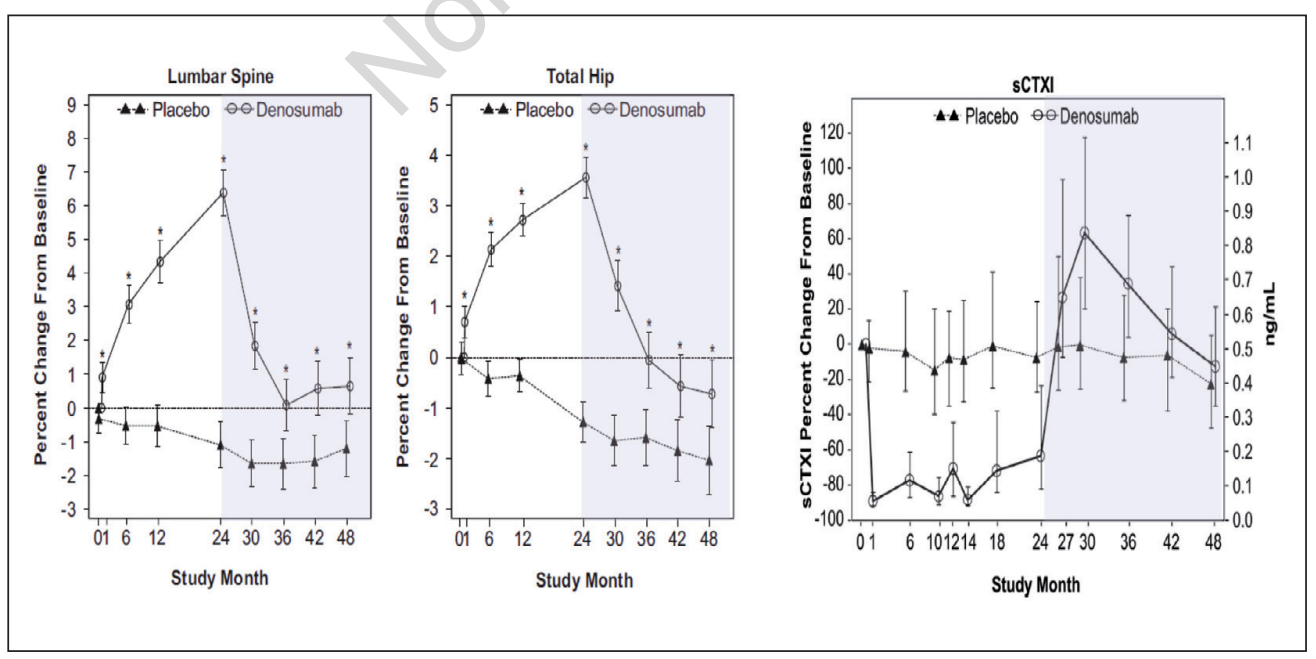

Figure 10 - BMD and serum CTX variation (bone turnover marker) after discontinuing treatment with denosumab (shadowed area). Serum CTX increases to levels higher than baseline (21). 
Ibandronate and risedronate discontinuation

These bisphosphonates have a tail effect relatively limited and bone turnover and BMD levels return to basal levels within a year. If an interruption of the treatment is planned (for example for a surgical or a dental operation) this should not be extended over 6 months in patients at high risk of fracture.

\section{Alendronate o zoledronate discontinua- tion}

ALN and ZOL are among the drugs with the best evidence of reducing the risk of all kinds of fracture. They are also the drugs with the most persistent tail effect concerning bone turnover, BMD values and fracture risk. The anti-fracture efficacy is partially lost after treatment discontinuation for vertebral fractures, while the protection is extended for at least 2 years for the risk of non-vertebral fractures. Therefore for these two drugs it is conceivable to plan short discontinuations of the treatment and this translates in an additional advantage in pharmaco-economic terms.

The issue of the selection of the patients candidate for a period of treatment vacation has recently been addressed by the NIH in the USA. As we have seen, with treatment discontinuation vertebral frac- ture risk slightly rises, with a the Relative Risk (Fig. 11) rising by $50 \%$ for both ALN and ZOL versus patients who continue treatment. However, the Absolute Reduction and therefore the NNT (the number of patients to treat for preventing a fracture) depends on the original risk of fracture. For ALN in the whole population included in the FLEX trial (9) the NNT was 34. However, in patients at high risk, such as those identified by Nota 79 (previous vertebral or femoral fracture or BMD values <-3.0) the NNT was merely 17 (Fig. 11). In high risk patients (Fig. 4) the prosecution of treatment grants also a significant higher protection from non-vertebral fractures (10). These evaluations were at the basis of the recommendations recently published by NIH(3). Treatment with ALN or ZOL may be interrupted after 3-5 years only in patients in whom fracture risk is low or lowered because of the treatment itself. It is recommended to never discontinue treatment in patients with one or more prevalent osteoporotic fractures or in whom the BMD values are still inferior to -2.5 ( $\mathrm{T}$ score).

The individuation of the patient in whom it is possible to discontinue treatment also depends upon the adherence to the treatment itself; i.e.: in patients with a mean adherence in the last 3-5 years inferior to 80\%, discontinuation is never recommended.

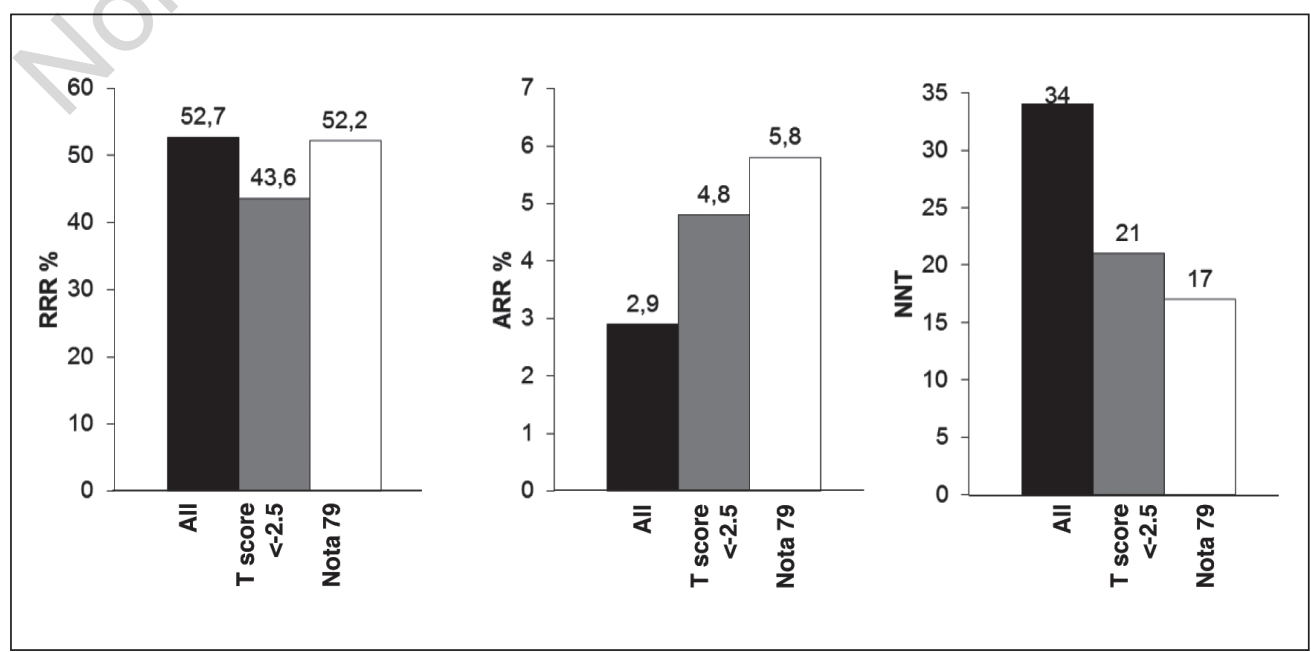

Figure 11 - Relative Risk Reduction (RRR \%), Absolute Risk Reduction (ARR \%) and corresponding Number Needed to Treat (NNT) for vertebral fractures in patients attending the FLEX trial (9), extension of the FIT trial (6). 
The duration of the interruption should be planned on an individual base. In patients with a moderate initial fracture risk a reassessment one year after discontinuation is appropriate. In patients at high initial risk (i.e. with a pre-treatment $\mathrm{T}$ score $<-3.0$ ) or with other risk factors (i.e. corticosteroid therapy, smoke, thinness, age $>5$ years) discontinuation should not exceed 8 months for ALN and 1-2 years for ZOL (therefore 2-3 years from last infusion). With most anti-reabsorptive treatments, the full antifracture efficacy is achieved within few months after commencing therapy (26). Treatment prosecution is associated with important densitometric increases which apparently are not associated with additional benefits in terms of anti-fracturative efficacy. For some drugs (Risedronate and Strontium Ranelate) the anti-fracture efficacy seems even to lessen after the first year despite continuous treatment. These observations are consistent only with an important anti-fracture effect related to bone turnover reduction already fully expressed after few weeks since the start of the therapy (27). For this reason it is preferable not to extend the discontinuation for more than 6 and 12 months for both RIS and ALN. The discontinuation period for $\mathrm{ZOL}$ is not well established but can exceed a year (therefore more than 2 years from last infusion).

Final recommendations on the strategies to follow for discontinuation of postmenopausal osteoporosis treatment are summa- rized on the Table II, where the fracture risk is esteemed with DeFRA $(28,29)$.

\section{TREATMENT DURATION AND PHARMACO-ECONOMIC IMPLICATIONS}

In Table III are listed the anti-fracture efficacy data for the most commonly reimbursed drugs in Italy. The data are extracted from meta-analysis or Health Technical Assessments (30) or from pivotal trials when these were the only available data. Cochrane meta-analysis are available for Alendronate, Risedronate and Strontium Ranelate (31). For Teriparatide and denosumab only data from the pivotal trials were considered. Ibandronate, Raloxifene and Basedoxifene were not included in the table because there is no evidence of efficacy for non-vertebral and femoral fractures. In a typical population for Nota 79 (1113,32 ), the 5 years incidence is ca. $30 \%$, $25 \%$ and $7 \%$ for vertebral, non-vertebral and femoral fractures, respectively. These esteems make possible to calculate the reduction of the absolute risk (ARR\%) and therefore the cost for every fracture avoided assuming a cost per 5 years of treatment equal to: Alendronate $€ 850$, Risedronate $€$ 800 , StrontiumRanelate $€ 3000$, Teriparatide $€ 8500+500 €$ for Alendronate for 3-4 years, Denosumab € 2000.

The cost for avoided fracture is calculated multiplying the treatment cost for the

Table II - Final recommendations on the strategies to follow for discontinuation of postmenopausal osteoporosis treatment

\begin{tabular}{|c|c|c|}
\hline Drug & Fracture Risk DeFRA & After-discontinuation recommendations \\
\hline All drugs & $>30 \%$ (Note 79 ) & No discontinuation is advised \\
\hline Denosumab & - & $\begin{array}{l}\text { Observe a cycle of therapy with bisphosphonates six months after last } \\
\text { administration. }\end{array}$ \\
\hline \multirow{2}{*}{$\begin{array}{l}\text { Estrogens- } \\
\text { SERMS }\end{array}$} & $<20 \%$ & Non pharmacological prevention. Reassess after one or two years. \\
\hline & $20-30 \%$ & $\begin{array}{l}\text { Resume the treatment or alternative treatment (bisphosphonates) after } \\
\text { two months. }\end{array}$ \\
\hline \multirow{2}{*}{$\begin{array}{l}\text { Risedronate } \\
\text { Ibandronate }\end{array}$} & $<20 \%$ & Non pharmacological prevention. Reassess after six months. \\
\hline & $20-30 \%$ & Resume therapy within four months. \\
\hline \multirow{2}{*}{$\begin{array}{l}\text { Alendronate } \\
\text { Zoledronate }\end{array}$} & $<20 \%$ & Non pharmacological prevention. Reassess after one or two years. \\
\hline & $20-30 \%$ & Resume treatment within eight-twelve months. \\
\hline
\end{tabular}


Number Needed to Treat (NNT for 5years) (therefore 100/RRA\%) (Tab. IV).

Since a drug reduces all three kinds of frac- ture all together, a cost for an arbitrary mix was generated assuming the cost of femoral fracture equal to the cost of 2 vertebral

Table III - Relative risk reduction (RRR \%) for vertebral, non-vertebral and femoral fractures (see text for details).

\begin{tabular}{|l|l|l|l|}
\hline Drug & RRR vertebral fractures & RRR non-vertebral fractures & RRR femoral fractures \\
\hline Alendronate & $45 \%$ & $23 \%$ & $40 \%$ \\
\hline Risedronate & $39 \%$ & $20 \%$ & $26 \%$ \\
\hline Zoledronate & $70 \%$ & $24 \%$ & $40 \%$ \\
\hline Strontium ranelate & $37 \%$ & $14 \%$ & $15 \%$ (NS) \\
\hline Teriparatide & $65 \%$ & $53 \%$ & $35 \%$ (NS) \\
\hline Denosumab & $68 \%$ & $20 \%$ & $40 \%$ \\
\hline
\end{tabular}

Table IV - Absolute risk reduction (ARR\%) in a typical note 79 patient for vertebral, non-vertebral and femoral fracture (see text for details) and cost to avoid every single fracture.

\begin{tabular}{|c|c|c|c|c|c|c|c|c|}
\hline \multirow[t]{2}{*}{ Drug } & \multicolumn{2}{|c|}{ Vertebral fractures } & \multicolumn{2}{|c|}{$\begin{array}{l}\text { Non-vertebral } \\
\text { fractures }\end{array}$} & \multicolumn{2}{|c|}{ Femoral fractures } & \multicolumn{2}{|c|}{$\begin{array}{l}\text { Cumulative: } \\
\text { vertebral } x 1+\text { non- } \\
\text { vert } x 0.5+\text { femur } x 2\end{array}$} \\
\hline & RRA $\%$ & $\begin{array}{l}\text { Cost } \\
€ \times 1000\end{array}$ & RRA $\%$ & $\begin{array}{l}\text { Cost } \\
€ \times 1000\end{array}$ & RRA $\%$ & $\begin{array}{l}\text { Cost } \\
€ \times 1000\end{array}$ & RRA $\%$ & $\begin{array}{l}\text { Cost } \\
€ \times 1000\end{array}$ \\
\hline Alendronate & $13,5 \%$ & 6,3 & $5,75 \%$ & 14,8 & $2,8 \%$ & 30,3 & $21,7 \%$ & 3,9 \\
\hline Risedronate & $11,7 \%$ & 6,8 & $5,0 \%$ & 16,0 & $1,82 \%$ & 43,9 & $17,8 \%$ & 4,5 \\
\hline Strontium ranelate & $11,1 \%$ & 27,0 & $3,5 \%$ & 85,7 & $1,05 \%$ & 285,7 & $15,0 \%$ & 19,3 \\
\hline Teriparatide & $19,5 \%$ & 46,1 & $13,25 \%$ & 66,7 & $2,45 \%$ & 367,3 & $31,1 \%$ & 28,9 \\
\hline Denosumab & $20,4 \%$ & 9,8 & $5,0 \%$ & 40,0 & $2,8 \%$ & 71,4 & 28,5 & 7,0 \\
\hline
\end{tabular}

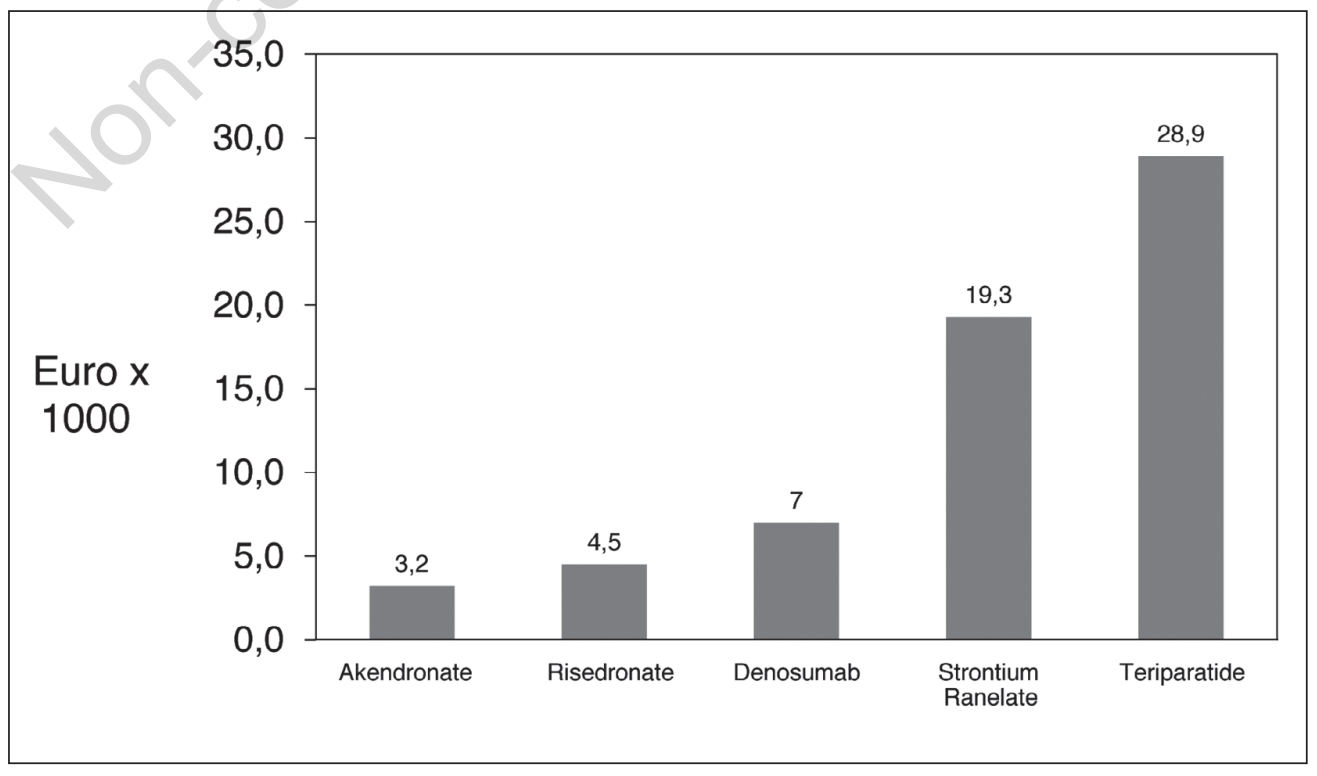

Figure 12 - Cost per fracture avoided in a 5 years period assigning a "therapeutic vacation" of 8 months every 5 years to Alendronate (for all the other drugs a "tail" effect cannot be attributed). 
fractures and the cost of a non-vertebral fracturehalf of that of a vertebral fracture.

As we have seen, in a vast proportion of patients, a treatment with an adequate adherence to ALN and ZOL allows a treatment "vacation" every 5 years without consequences on fracture risk. This lowers the cost for fracture avoided with ALN for an additional $18 \%$ (Fig. 12). For all these esteems ZOL was not included since it is administered only in Hospitals, but the cost-effectiveness is very similar to that esteemed for Alendronate.

\section{SUMMARIZING CONCLUSIONS}

The pharmacological treatment for postmenopausal osteoporosis is justified only for patients at very high risk of fracture. This can now be easily esteemed with FRAX or DEFRA (27). After a few years of treatment the risk is likely to decrease and a treatment vacation might be taken into account, but the supplementation with calcium and vitamin $\mathrm{D}$ and the removal of risk factors should continue.

The decision of discontinuing the treatment depends on the drug used and on the re-assessment of fracture risk after at least 3-5 years of treatment. A treatment course with Teriparatide must always be followed by therapy with anti-reabsorptive (e.g.: bisphosphonates). Denosumab should never be discontinued and, if that occurs, a treatment course with bisphosphonates should be considered in order to prevent the rebound of bone turnover. Discontinuation of estrogens, Raloxifene, Basedoxifene, Risedronate and Ibandronate is associated with the quick loss of the acquired benefits, and therefore the discontinuation should never exceed 6 months.

Treatment with ALN and ZOL is characterized by an important "tail effect". Thus, after 5 years of optimal adherence, a treatment discontinuation might be planned in low-risk patients $(<30 \%$ according to DeFRA), but not in patients with previous severe fractures or in whom the risk remains high even after years of treatment (Fig. 13). The possibility of implementing "treatment vacations" increases the cost-effectiveness profile for ALN and ZOL making these therapies of Nota 79 really cost-effective; i.e. the cost of treatment in the framework of the Nota 79 is now lower than the hospital costs for the same fracture!

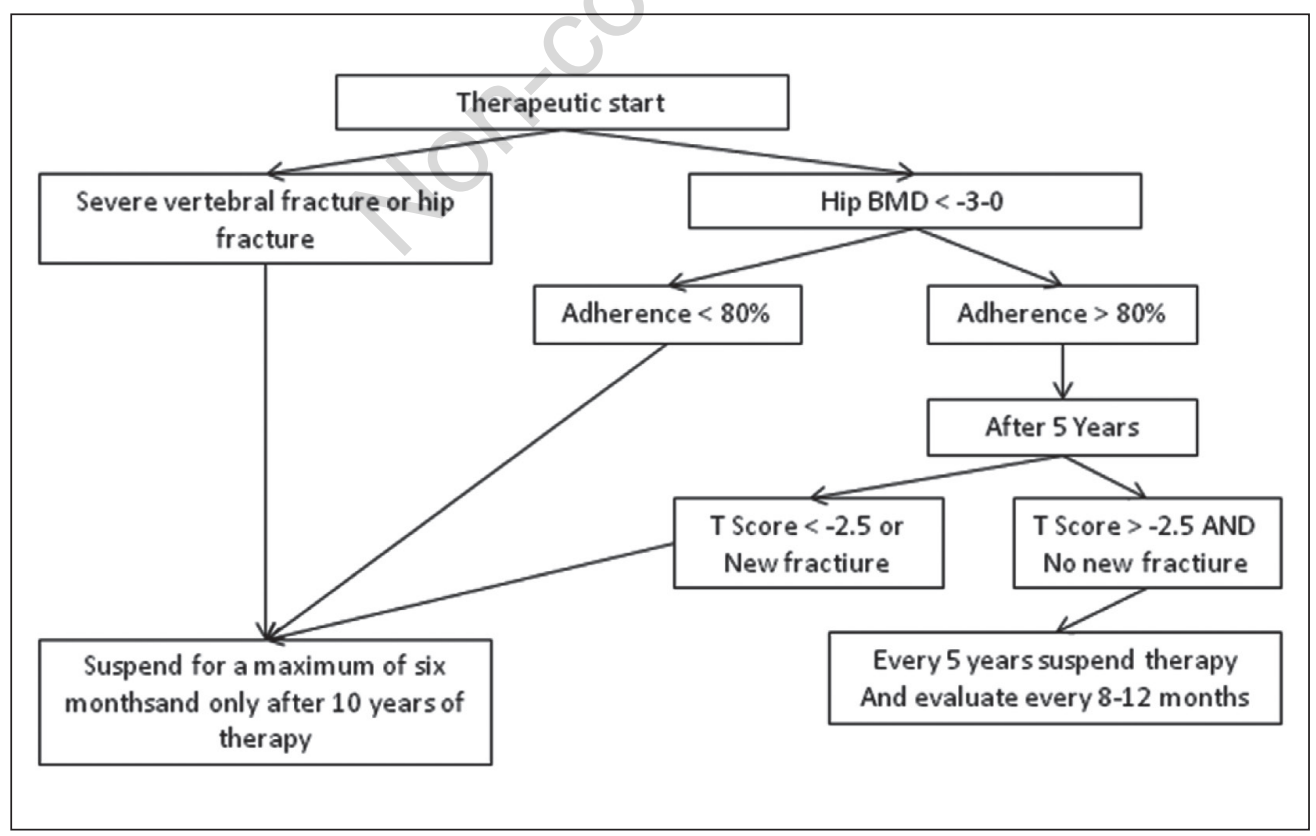

Figure 13 - Flow chart of the behavior to follow concerning the duration of treatment with Alendronate. 


\section{REFERENCES}

1. Adami S, Bertoldo F, Brandi ML, et al. Guidelines for the diagnosis, prevention and treatment of osteoporosis. Reumatismo. 2009; 61: 260-84

2. Macedo JM, Macedo CR, Elkis H, De Oliveira IR. Meta-analysis about efficacy of anti-resorptive drugs in post-menopausal osteoporosis. J Clin Pharm Ther. 1998; 23(5): 345-52.

3. Whitaker M, Guo J, Kehoe T, Benson G. Bisphosphonates for osteoporosis-Where do we go from here? N Engl J Med. 2012; 366: 2048-51

4. Liberman UA, Weiss SR, Bröll J, et al. Effect of oral Alendronate on bone mineral density and the incidence of fractures in postmenopausal osteoporosis. The Alendronate Phase III Osteoporosis Treatment Study Group.N Engl J Med. 1995; 333: 1437-43.

5. Bone HG, Hosking D, Devogelaer JP, Alendronate Phase III Osteoporosis Treatment Study Group et al. Ten years' experience with Alendronate for osteoporosis in postmenopausal women. N Engl J Med. 2004 350: 1189-99.

6. Black DM, Cummings SR, Karpf DB, et al. Randomised trial of effect of Alendronate on risk fracture in women with existing vertebral fractures. Fracture Intervention Trial Research Group. Lancet. 1996; 348: 1535-41.

7. Black DM, Thompson DE, Bauer DC, Fracture Intervention Trial et al. . Fracture risk reduction with Alendronate in women with osteoporosis: the Fracture Intervention Trial. FIT Research Group. J Clin Endocrinol Metab. 2000; 85: 4118-24.

8. Cummings SR, Black DM, ThompsonDE, et al. Effect of Alendronate on risk of fracture in women with low bone density but without vertebral fractures. JAMA. 1998; 280: 2077-82.

9. Black DM, Schwartz AV, Ensrud KE, FLEX Research Group, et al. Effects of continuing or stopping Alendronate after 5 years of treatment: the Fracture Intervention Trial Longterm Extension (FLEX): a randomized trial. JAMA. 2006; 296: 2927-38.

10. Schwartz AV, Bauer DC, Cummings SR, FLEX Research Group, et al. Efficacy of continued Alendronate for fractures in women with and without prevalent vertebral fracture: the FLEX trial. J Bone Miner Res. 2010; 25: 976-82.

11. McClung MR, Geusens P, Miller PD, et al. Effect of Risedronate on the risk of hip fracture in elderly women. Hip Intervention Program Study Group. N Engl J Med. 2001; 344: 33340.

12. Harris ST, Watts NB, Genant HK et al. Effects of Risedronate treatment on vertebral and nonvertebral fractures in women with postmenopausal osteoporosis: a randomized controlled trial. Vertebral Efficacy With Risedronate Therapy (VERT) Study Group. JAMA. 1999; 282: 1344-52.

13. Reginster J, Minne HW, Sorensen $\mathrm{OH}$ et al. Randomized trial of the effects of Risedronate on vertebral fractures in women with established postmenopausal osteoporosis. Vertebral Efficacy with Risedronate Therapy (VERT) Study Group. Osteoporos Int. 2000; 11: 83-91.

14. Watts NB, Chines A, Olszynski WP, et al. Fracture risk remains reduced one year after discontinuation of Risedronate. Osteoporos Int. 2008; 19: 365-72.

15. Eastell R, Hannon RA, Wenderoth D, Rodriguez-Moreno J, Sawicki A. Effect of stopping Risedronate after long-term treatment on bone turnover. J Clin Endocrinol Metab. 2011; 96: 3367-73.

16. Black DM, Delmas PD, Eastell R, Reid IR, HORIZON Pivotal Fracture Trial, et al. Once-yearly zoledronic acid for treatment of postmenopausal osteoporosis. N Engl J Med. 2007; 356: 1809-22.

17. Black DM, Reid IR, Boonen S, Bucci-Rechtweg $C$, et al. The effect of 3 versus 6 years of zoledronic acid treatment of osteoporosis: a randomized extension to the HORIZON-Pivotal Fracture Trial (PFT). J Bone Miner Res. 2012; 27: 243-54.

18. Reid IR,Black DM, Eastell R, Bucci-Rechtweg $\mathrm{C}$ et al. Reduction in the Risk of Clinical Fractures after 1 a Single Dose of 2 Zoledronic Acid 5 mg. J Clin Endocrinol Metab. 2012 (in press).

19. Ravn P, Christensen JO, Baumann M, Clemmesen B. Changes in biochemical markers and bone mass after withdrawal of ibandronate treatment: prediction of bone mass changes during treatment. Bone. 1998; 22: 559-64.

20. Naylor KE, Clowes JA, Finigan J, Paggiosi MA, Peel NF, Eastell R. The effect of cessation of Raloxifene treatment on bone turnover in postmenopausal women. Bone. 2010; 46: 592-7.

21. Bone HG, Bolognese MA, Yuen CK et al. Effects of Denosumab treatment and discontinuation on bone mineral density and bone turnover markers in postmenopausal women with low bone mass. J Clin Endocrinol Metab. 2011; 96: 972-80.

22. Lindsay R, Scheele WH, Neer R, et al. Sustained vertebral fracture risk reduction after withdrawal of Teriparatide in postmenopausal women with osteoporosis. Arch Intern Med. 2004; 164: 2024-30.

23. Adami S, San Martin J, Muñoz-Torres M, Econs MJ, Xie L, Dalsky GP et al. Effect of Raloxifene after recombinant Teriparatide [hPTH(1-34)] treatment in postmenopausal women with osteoporosis. Osteoporos Int 2008; 19: 87-94 
24. Brown JP, Roux C, Törring O, Ho PR, BeckJensen JE, Gilchrist N, Recknor C, Austin M, Wang A, Grauer A, Wagman RB. Discontinuation of denosumab and associated fracture incidence: Analysis from the FREEDOM trial. J Bone Miner Res. 2012 Oct 29.

25. Agenzia Italiana per il Farmaco: AIFA. Available at: http://www.agenziafarmaco.it

26. Roux C, Seeman E, Eastell R, Adachi J, Jackson RD, Felsenberg D, et al. Efficacy of Risedronate on clinical vertebral fractures within six months . Curr Med Res Opin. 2004; 20: 433-39.

27. Riggs BL, Melton LJ 3rd, O'Fallon WM. Drug therapy for vertebral fractures in osteoporosis: Evidence that decreases in bone turnover and increases in bone mass both determine antifracture efficacy. BONE. 1996; 18 (Suppl. 3): 197S-201S.

28. DeFRA http://defra-osteoporosis.it

29. Adami S, Bianchi G, Brandi ML, et al. Vali- dation and further development of the WHO 10-year fracture risk assessment tool in Italian postmenopausal women: project rationale and description. Clin Exp Rheumatol. 2010; 28: 561-70.

30. NICE. Alendronate, etidronate, Risedronate, Raloxifene, Strontium Ranelate and Teriparatide for the secondary prevention of osteoporotic fragility fractures in postmenopausal women (amended). www.nice.org.uk/TA161 (last access May 2012).

31. Cochrane reviews for osteoporosis. http:// www.thecochranelibrary.com/details/ browseReviews/577511/Osteoporosis.html. (Last access may 2012).

32. Adami S, Isaia G, Luisetto G, Minisola S, Sinigaglia L, Gentilella R, Agnusdei D, Iori N, Nuti R; ICARO Study Group. Fracture incidence and characterization in patients on osteoporosis treatment: the ICARO study. J Bone Miner Res. 2006; 21 (10): 1565-70. 